\title{
The Translation of Culture-loaded Tourism Texts from Perspective of Relevance Theory
}

\author{
Yining Zhang \\ Changchun University of Science and Technology, China \\ Zitu Lv \\ China Road and Bridge Corporation, China \\ Chunhua Feng \\ Changchun University of Science and Technology, China
}

\begin{abstract}
The translation versions of tourism texts are playing an important role in attracting travellers domestic and abroad, and the Chinese government and translators are paying great attention on the translation of tourism texts. This paper is mainly about the relationship between the translation of tourism texts and relevance theory, discusses the cognitive principle of relevance and communicative principle of relevance and translation, and focuses on gloss translation, especially transliteration with internal gloss, which is more helpful to come up with an accurate 'equivalent' in understanding the corresponding information as well as the spread of the national culture.
\end{abstract}

Index Terms - tourism texts, relevance theory, optimal relevance, gloss translation, transliteration with internal gloss

\section{INTRODUCTION}

Since tourism texts can offer tourists or potential tourists a lot of information or therefore persuade them to travel to the area mentioned, tourism texts are attractive and informative, and play a very important role in tourism. In order to attract more tourists abroad or make the foreign tourists understand the scenery better, a lot of Chinese tourism texts are translated into different other languages, especially English. In the process of translating, the tourism texts concerning the local or native culture are the most difficult for translators. This paper aims to mainly discuss the translation of cultural-specific terms and expressions in Chinese tourism texts from the perspective of relevance theory.

\section{RELEVANCE THEORY}

The criterion proposed in Relevance is based on a fundamental assumption about human cognition. The assumption is that human cognition is relevance-oriented: we pay attention to information that seems relevant to us (Wilson, 1994). Relevance is defined in terms of contextual effect and processing effort. The core of relevance theory is about the nature and the process of human verbal communication. The audience can get many different kinds of comprehension to an utterance. However, it is impossible for the audience to accept all kinds of comprehension equally. In comprehension and interpretation of an utterance the audience is guided by relevance. The responsibility for avoiding misunderstanding lies in the speaker, so that all the hearer has to do is to go ahead and use whatever code and contextual information come most easily to hand (Wilson and Sperber, 1986, p.43). A logical implication can neither derive from the new information itself, nor from the context alone. The only way to drive an implication is by combining the new information and the context. Hence, we claim that newly-presented information is relevant in a context when and only when it achieves contextual effects in that context. Other things being equal, the greater the contextual effects are, the greater the relevance is.

Relevance theory holds that human communication intends to search for optimal relevance, i.e. to achieve adequate contextual effects without too much processing effort. When a speaker goes about communicating with others, he/she automatically intends to communicate the presumption that he/she will say something that is supposed to be optimally relevant to the audience.

Communication is achieved by the communicator providing evidence of his/her intentions and the audience inferring his/her intentions from the evidence, on the basis of the shared common knowledge. Relevance theory develops 2 principles about the role of relevance in cognition and in communication.

Cognitive principle of relevance: human cognition tends to by geared to the maximization and in relevance.

Communicative principle of relevance: every act of communication conveys a presumption of its own optimal relevance.

\section{ReLEVANCE THEORY AND TRANSLATION}


In the history of translation studies, several scholars on translation, such as House (1977), Gutt (1991), Toury (1980,1995), Newmark (1981/1988) and Venuti (1995) have greatly contributed to the development of translation studies in terms of practice and theoretical construction. Combining the relevance theory and translation, Gutt (1991) applied relevance theory to translation studies in his PHD thesis, Translation and Relevance: Cognition and Context, which is a widely-spread theory of linguistic pragmatics in recent years.

Gutt (1998) claims that the purpose of implicit translation, such as tourism texts, advertisements, is not to provide the source information, since the relevance of source information and the target information does not play any role, thus covert translation can be realized as a writing of a new text in a new language. However, the new text must be relevant to the source text in information expression. Hence, the process of translation is restrained by relevance theory, and translation is a process of dynamic manifestation-inference of the source language. A translator should presume the reporter's communicational act and search for optimal relevance that can be conveyed to the reader. On this basis, this paper addresses the cognitive account in term of relevance theory in interpretation and understanding of the acceptable translation of tourism text, especially the translation of the cultural-specific information.

\section{Translation Of Chinese Tourism TeXT}

The most basic assumption of relevance theory is that every aspect of communication and cognition is governed by the search for relevance. As a theory of language communication, Relevance Theory is an ostensive-inferential interpretation, which involves the tertiary dynamic relationship between the author, the translator and the reader of the translated text. Translation from the relevance point of view employs the main concept such as "ostensive, inference and relevance" in translation, i.e. seeking optimal relevance anticipation in translating the source text to the acceptable and understandable text for foreigner readers. Translation should make it adequately relevant to the readers of the target texts by providing sufficient contextual effects; meanwhile, translation should produce the intended interpretation in an economical method of the possibility of least processing efforts.

\section{A. The Ostensive-inferential Model and Translation}

Tourism texts include a nation's historical and cultural background, and people's ways of living and thinking. Generally speaking, tourism texts are written for visitors who share the same or similar cultural background. Tourism texts are the ways to preserve and spread the culture of a nation or a community, which is always unique to that nation or community.

The aim of tourism text is often to attract the reader's attention and then make a sale, as well as preserving the unique culture. In translating tourism text with some original culture-loaded terms, relevance theory is playing important roles in making the translated text relevant to the cognitive environment of the foreign readers.

The translators are expected to generate presumptions of relevance in the target language which is similar to the ones originate from the source message. It is crucial to achieve the communicative goals between the source text author and the target text readers. Hence, there must be the adaptation process which helps the understanding of similar cognitive effects and inferences. The translator is supposed to help the target tourism text readers adapt their expectations to a new cultural environment. Therefore target tourism text readers can build new assumptions in the light of the contextual effects and understand the implicit information in the source tourism text.

In perspective of relevance theory, translation is regarded as communication. According to relevance theory, communication not only requires encoding and decoding processes, but also involves inference of the implicit information. As a means of communication, translation is also based on the human beings' inferential capacity. The intention of writer can be perceived by the readers because of the shared cognitive environment. The success of translation depends on, to some extent, the manifestation and mutual manifestation of both the translators' and readers' cognitive environment. The comprehension of the mentioned cultural information follows the ostensive-inferential model.

The code model provides the framework for a general theory of communication and verbal communication, while the inferential model describes comprehension as an inferential process. Thus translation has been described as a process of inferential recognition of writer's and translator's intentions. According to the code model, communicative function is the main function of language and the understanding of translation is achieved by encoding and decoding messages.

Some implicit information is context-dependent, which restrict the communicability of the literary texts in another context. In the process of translation, the translator must notice the restriction of dynamic context in the perspective of culture and history. In the ostensive-inferential process of translation, there are two kinds of communication involved, namely, the primary communication between the original author of the tourism text and the translator and the secondary communication between the translator and the target reader of the target tourism text. In the secondary communication process, the translator should make right assumptions of the target tourism text readers about their cognitive environment and estimate their cognitive facilities. The tourism text readers receive the encoded message and decode it to arrive at the meaning the translator intended. This can be visualized as follows:

Thought/intention of the author of the original tourism text $\Rightarrow$ encoded $\Rightarrow$ transmitted $\Rightarrow$ decoded $\Rightarrow$ intention/thought understood by the translator. 
Translator's thought/intention $\Rightarrow$ encoded $\Rightarrow$ transmitted $\Rightarrow$ decoded $\Rightarrow$ intention/thought understood by the readers of the tourism text.

\section{B. Optimal Relevance of Translated Text}

Sperber and Wilson (1986) define a notion of optimal relevance which is meant to spell out what the hearer is looking for in terms of effort and effect:

An utterance, on a given interpretation, is optimally relevant if and only if:

(a) it achieves enough contextual effects to be worth the hearer's attention;

(b) it puts the hearer to no gratuitous processing effort in achieving those effects.

Relevance theory requires the optimal relevance of utterance and context in order to achieve the communicators' implicature. Translators are to choose the most relevant stimuli to manifest his interpretation and decoding of the intentions of the original text to the target reader.

The employment of relevance theory in translation can facilitate the understanding of information in the tourism text through their previous experience and knowledge. Optimal relevance guides the readers of the tourism texts to expect the contextual information needed for the correct decoding is readily accessible. If the context is right, the translated text is supposed to yield an interpretation that is worth the effort the readers has made in processing the information. The task of translators is to achieve the optimal relevance, so that the target readers can achieve adequate contextual effects without expending gratuitous processing effort, i.e. to ensure optimal relevance.

Considering the readers' perception of the cognitive environment, translators will make their translation acceptable by relating to the environment foreign readers are familiar with. Translators will design the translation in such a way that it "resembles the original closely enough in relevant respects' (Wilson \& Sperber, 1988, p.137)

Since translation is the essential type of intercultural communication, cultural knowledge is quite important to translators. Basically, what the translator does is to take an object rooted in one culture and transfer it into a product of the code of another culture. Thus, part of the cultural knowledge the translator must deal with is knowledge of cultural models, but the translator must also know about the cultural values associated with language itself. Culture and intercultural competence and awareness that rise out of experience of culture, are far more complex phenomena than it may seem to the translator. The more a translator is aware of complexities of differences between cultures, the better a translator s/he will be.

Translators can either bring the reader to him or bring the writer to him. However, the translation of tourism text with culture-loaded information is different from the translation of other forms of translation in that specific culture and history in the tourism texts are supposed to be exposed to foreign readers or visitors. Since domestication is a practice that leads the readers to recognize their own culture in a text which has been produced in another culture (Venuti, 1995), foreignization should be employed in the translation of the tourism texts in order to retain the original flavor and spread the culture and history of a nation. However, foreignization, which tend to ignore the dominant cultural values in the target language, is likely to make it difficult for foreign readers to "go ahead and use whatever code and contextual information come most easily to hand"(Wilson and Sperber, 1986, p.43), and the optimal relevance is seldom achieved. Neither domestication alone nor sole foreignization in translation is effective in making the translated texts optimally relevant and acceptable for readers of different cultural backgrounds. The following is the method the author prefers to translate culture-loaded tourism texts, which could make the translated text optimally relevant to the cognition and background knowledge of the foreign readers.

\section{Gloss Translation}

Gloss translation is designed to permit the reader to identify himself as fully as possible with a person in the source language context, and to understand as much as he can of the custom, manner of thought and means of expression (Venuti, 2000), in which the meaning of the text in its original language is explained, sometimes in another language. As such, glosses can vary in thoroughness and complexity, from simple marginal notations of words one reader found difficult or obscure, to entire interlinear translations of the original text and cross references to similar passages.

In tourism text translating process, the translators intend to convey certain cultural message, which is actively helping the readers to recognize the translated texts. However, either the above mentioned domestication or foreignization can hardly make such message conveyed successfully and optimally, if the understanding of the message only depends on the knowledge of English alone. The writer of the original text was concerned for the text to be optimally relevant to the context shared by the native speakers of the language and himself, while he/she would not be concerned with the possible foreign readers whose context might not be optimally relevant. Hence, it is the translators' task to make the translated text be optimally relevant in the target context. The translation which best satisfies the readers' expectation of relevance would be chosen by readers while they are decoding the information mentioned in the translated tourism text.

Obviously, contextual effects do not come free and cost some mental effort to derive. The greater the effort the translators make, the higher the relevance will be. From the relevance-theory point of view, transliteration with internal gloss can guide the readers in their search for optimal relevance in understanding culture-loaded texts. The core relation between the translation and the original is one of interpretive resemblance, which is also defined as the sharing of implicatures and implicatures between the two texts. It is the reader's responsibility to familiarize himself with the 
historical and cultural background of the text to ensure correct understanding. Through gloss translation, especially transliteration with internal gloss, the translator intervenes and provides various explanatory notes to the text to help the readers overcome the problem caused by the different social and cultural background knowledge in different nations or different communities.

For the translation of some culture-loaded information, gloss translation is a good method to achieve the manifestation and optical relevance by building new assumptions in the light of the contextual effects. Contextual effect, one of the two main factors of relevance theory controls the degree of relevance. It is the production of the interplay of the old message and the new message: the new message combines with the current contextual assumptions can produce new contextual implication; the new message strengthens existing contextual assumptions; the new message contradicts current contextual assumptions and eliminates the current contextual assumptions.

China is famous for its long history and beautiful scenery, with a lot of spots impressive and attractive. The translation of these spots is worth discussion. According to Hermans (1999), translation can and should be recognized as a social phenomenon, a cultural practice. Difference between cultures cause more complications for translators that the language structure itself does. The tourism texts with cultural-specific expressions are difficult to translate because they are deeply rooted in the culture and values associated with the source language. In the process of translating the Chinese tourism text into English, the translated text with corresponding gloss can be considered as the new message, while information in foreigners' cognitive environment is the old message. So the translator should make his/her translation yield greater contextual effects by making fewer processing efforts. Successful translations are to create similar or identical contextual effect for foreign readers in order to make the foreign readers understand the communicative intention of the original tourism text. The following are the 2 versions of translation of a sentence from the introduction of Imperial City, Beijing:

A: The Imperial City is a section of the city of Beijing in the Ming and Qing dynasties, and was surrounded by a wall and accessed through six gates, with the Forbidden City at its center, whose construction took 14 years, and was finished in 1420 .

B. The Imperial City is a section of the city of Beijing in the Ming and Qing dynasties, and was surrounded by a wall and accessed through six gates, with the Forbidden City at its center, whose construction took 14 years, and was finished in 1420, 72 years before Christopher Columbus discovered the New World.

Obviously, Version B with gloss is relevant to the readers' cognitive environment, which ensures optimal relevance to facilitate the target readers achieve adequate contextual effects without expending gratuitous processing effort. Hence, translations should be oriented toward appropriateness and acceptability to language and culture of the target test readers.

Similarly, the following is an example of footnote and interlinear gloss, which offers further background knowledge for foreign readers' understanding of the language and corresponding culture:

Hanshan Temple(1)(Hanshan si), is located in Maple Bridge Town (Fengqiao Town) in the west outskirts of Suzhou, and was built during Tianjian Period of Liang Dystany (A.D.502-519) with a long history of more than 1400 years. It used to be one of the ten most famous temples in China. Hanshan Temple became well known after the Tang poet Zhang Ji wrote a famous poem when he passed by the temple on a small boat. Two lines of the poem reads, 'outside the Suzhou City wall, I heard the sound of Hanshan Temple bell onboard the boat and felt its midnight spell'. On 31 December every year, Hanshan Temple holds the event of Striking the New Year's Bell, during which the superior of the temple strike the bell 108 beats and visitors can enjoy themselves at various celebrations.

Note(1): The Hanshan Temple is named after one of the abbots in this temple, whose holy name is "Hanshan".

As is shown in the above example, transliteration with internal gloss is also frequently employed in order to come up with an accurate 'equivalent' in understanding the corresponding information. Zhu Geliang, Xi Shi, Li Bai in Chinese are the typical examples, to whom a lot of famous sightseeing resorts are related. The translation of them or their stories needs attention of the translators and has great influence on readers and their understanding of original texts. Domestication of translating them into such familiar figures as King Salomon ,Helen, and Shakespeare will make the translated texts lose the original flavor and the purpose of spreading traditional culture in vain; while, foreignization of translating them directly into Chinese Pinyin will confuse the foreign readers. Thus, transliteration with internal gloss is effective in translation of the above information. If Zhu Geliang is translated as Zhu Geliang, the Chinese wiseman in Three Kingdom period, Li Bai, the Chinese Shakespeare in Tang Dynasty; Xi Shi, Chinese Helen in Spring-Autumn Period, both the relevance and maintenance of Chinese culture and history is achieved. Transliteration with internal gloss can widen the contextual knowledge of the target readers, which is helpful for the achievement of optimal relevance.

A translator aiming at optimal relevance must have intended to achieve some additional effects not achievable simply by translating literally. No attempt to bridge a wide cultural gap could erase the trace of the foreign setting, which results in expressions deeply imbedded in the very thought structure of the message. Transliteration with internal gloss can facilitate the cultural gap by manifesting the foreign trace, which improves the contextual effect. Take the famous sightseeing spots in Shaoxing, the hometown of Chinese great writer, Luxun as an example: Bai Cao Tang is translated as Baicao Garden, a waste vegetable plot that made a paradise for little LuXun; Such translation not only offers the background knowledge for understanding, but also retain the flavor in Chinese. Tianchi (Heavenly Lake), and Luti Cave 
(the Deer-hoop-shaped Cave) in Changbai Mountain in Jilin province are now translated with internal gloss in order to keep the original flavor of the culture involved. Similarly, one of the famous halls in Imperial City in Beijing, Taihe Dian is translated as Taihe Hall (The Throne Hall of Supreme Harmony). Other examples are like Zhong He Dian (Hall of Complete Harmony), Qian Qing Men (Gate of Heavenly Purity), Lu Gou Qiao (The MarcoPolo Bridge) Da Guang Yuan (The Grand View Garden), Shi San Ling (The Ming Tombs), Yong Shou Gong (Palace of Eternal Life). Such a way of translation enables translated text optimally relevant to the context shared by the foreign readers; Meanwhile, it will provide optimally relevant information, which is conveyed by the spot itself.

\section{CONCLUSION}

Translators are to break down the barriers caused by linguistic and cultural factors between different cultures and produce the translated texts, which are optimally relevant and easy for foreign readers to interpret. Relevance theory is a strongly effective and efficient principle which is likely to be employed to guide translation, especially the translation of tourism texts involving culture. Consideration and manifestation of the readers' perception of the cognitive environment will make the translation optimally relevance and acceptable. Gloss translation helps translators manifest their intention to achieve some additional effects not achievable simply by translating literally. From the perspective of spreading one country's language and culture, gloss translation, especially transliteration with internal gloss can help achieve the optimal relevance of cultural-load tourism text, and is a most efficient way to make foreign readers understand the source text, appreciate the original culture of the source text and dream to travel to the places which are mentioned in the tourism texts.

\section{REFERENCES}

[1] Blakemore, D. (1992). Understanding Utterances. Blackwell, Oxford.

[2] H. Minabad, Hassan. (2004). "Culture in Translation and Translation of Culture Specific Items". Translation Studies. 5, 2.: $31-46$

[3] Hatim, Basil and J. Munday. (2006). Translation an Advance Resource Book. London and New York: Routledge.

[4] Gutt, Ernest-August. (1991). Translation and relevance: Cognition and context. Oxford \& Cambridge, MA: Basil Blackwell.

[5] Gutt, Ernest-August. (1998). Pragmatics aspects of translation: Some relevance-theory observations. In Leo Hickey, ed., 41-53.Munday, Jeremy. 2001. Introducing Translation Studies. Tehran: Yalda Ghalam.

[6] Fawcett, P. (2000). Presupposition and Translation. Shanghai: Shanghai Foreign Language Education Press.

[7] Hermans. (1999). Translation in systems. Descriptive and System-Oriented Approaches Explained. Manchester, St. Jerome Publishing.

[8] Newmark, Peter. (1988). A Brochure Book of Translation. Tehran: Adab.

[9] Newmark, Peter. (2001). Approaches to Translation. Shanghai: Shanghai Foreign Language Education Press.

[10] Sperber, D. \& Wilson. D. (1986). Relevance: Communication and Cognition. Cambridge, Massachusetts: Harvard University Press

[11] Sperber, D. \& Wilson, D. (2005). Pragmatics. In F. Jackson \& M. Smith (eds) Oxford Handbook of Contemporary Philosophy. OUP, Oxford

[12] Toury, G. (1995). Descriptive Translation Studies and Beyond. Amsterdam and Philadelphia: Benjamins.

[13] Venuti, L. (1995). The Translator's Invisibility: A History of Translation. London \& New York: Routledge.

[14] Venuti L. (2000). The Translation Studies Reader. London: Routledge

[15] Wilson, D. (1994). Relevance and Understanding G. Brown, K. Malmkjaer, A. Pollitt \& J. Williams (eds) Language and understanding. Oxford University Press, Oxford: 35-58

[16] Wilson, Deirdre. (1996). Pragmatics. Entry in A. Kuper \& J. Kuper (eds ) The Social Science Encyclopedia 2nd Edition. Routledge, London

[17] Wilson, D. \& Sperber, D. (1989). Representation and relevance. In Ruth Kempson ed. Mental Representations: The Interface between Language and Reality. Ed. R.M.Kempson. Cambridge: Cambridge University Press.

[18] Wilson, D. \& Sperber, D. (2004). Relevance Theory. In L. Horn \& G. Ward (eds.) The Handbook of Pragmatics. Oxford, Blackwell

[19] http://www.topchinatravel.com/china-attractions/hanshan-temple.htm (accessed 12/10/2012)

Yining Zhang was born in Shuangcheng, Heilongiiang, China in 1974. She has received her M.A. degree in linguistics from Changchun University of Science and Technology, China in 2002.

She is currently an associate professor and post-graduate supervisor in the School of Foreign Languages, Changchun University of Science and Technology, Changchun, China. Her research interests include pragmatics and translation.

Zitu Lv was born in Changchun, China in 1987. She has received her M.A. degree in linguistics from Changchun University of Science and Technology, China in 2012, and is working in China Road and Bridge Corporation as an interpreter.

Chunhua Feng was born in Songyuan, China in 1974. She has received her M.A. degree in Business management from Changchun University of Science and Technology, China in 2005. She is currently a lecturer in the School of Economy Management, Changchun University of Science and Technology, Changchun, China. 